Case Report

\title{
Takotsubo Cardiomyopathy following a L2-L5 Laminectomy and Fusion In Situ with Bone Morphogenic Protein
}

\author{
John Weaver ${ }^{1}$ and Jason Eubanks ${ }^{2}$ \\ ${ }^{1}$ Case Western Reserve University School of Medicine, 11100 Euclid Avenue Cleveland, OH 44106, USA \\ ${ }^{2}$ Department of Orthopaedic Surgery, Division of Spine Surgery, Case Western Reserve University, School of Medicine, \\ Cleveland, 11100 Euclid Avenue Cleveland, OH 44106, USA \\ Correspondence should be addressed to Jason Eubanks; jason.eubanks@uhhospitals.org
}

Received 24 January 2013; Accepted 3 March 2013

Academic Editors: Z. H. Khan, P. Kumar, and J. Mayr

Copyright (c) 2013 J. Weaver and J. Eubanks. This is an open access article distributed under the Creative Commons Attribution License, which permits unrestricted use, distribution, and reproduction in any medium, provided the original work is properly cited.

\begin{abstract}
Takotsubo cardiomyopathy (TC) is a rare, transient cardiomyopathy, with symptoms mimicking myocardial infarction. It has been reported to typically occur in postmenopausal women and is often triggered by an intense physical or emotional event with stimulation of the sympathetic response; the exact etiology, however, is uncertain. Bone morphogenic protein (BMP) is widely used in spinal fusions and has been associated with numerous perioperative complications. BMP is known to stimulate sympathetic pathways. In this paper, we present the case of a patient with a 7-hour episode of TC after a spinal fusion with bone morphogenic protein. The patient's symptoms resolved and long-term followup has been uneventful. This is the first paper to describe TC in the setting of spine or other major orthopaedic surgery and it suggests another possible area for further investigation in peri-operative events potentially associated with the use of bone morphogenic protein.
\end{abstract}

\section{Introduction}

Takotsubo cardiomyopathy (TC) is a poorly understood, rare presentation of cardiac failure in postoperative patients. TC is also called broken heart syndrome or stressed cardiomyopathy.

It presents similarly to acute myocardial infarction but has a self-limited course. Little is known about the exact etiology of TC, but it usually occurs in postmenopausal women and is often triggered by an intense physical or emotional event; however, the exact etiology is uncertain [1]. Multiple etiologies have been proposed and the connection between TC and the sympathetic response has been studied extensively. Symptoms mimic a myocardial infarction, but there is often absence of significant atherosclerotic vascular disease and patients usually make a full cardiac recovery [2]. TC is associated with a mortality rate of only 1.1\% [3]. In this paper, we present the case of a patient with a 7-hour episode of TC after a spinal fusion with bone morphogenic protein (BMP). BMP is widely used in spinal fusions and has been associated with numerous perioperative complications [4].
BMP is known to stimulate sympathetic pathways $[5,6]$. The following case represents the first report of TC in a patient undergoing major orthopaedic or spine surgery.

\section{Case Report}

A 75-year-old woman with a history of smoking, gastroesophageal reflux disease, and hypertension who struggled with symptomatic neurogenic claudication secondary to severe, multilevel stenosis, and a degenerative scoliosis. She failed extensive nonoperative treatment and elected to pursue surgical intervention. She was taken to the operating room for an L1 to S1 laminectomy and L2-L5 fusion in situ with iliac crest bone graft and bone morphogenic protein (BMP). A single large, infuse sponge was employed. In this particular case, BMP was employed because of her smoking history and her multilevel pathology. Instrumentation was not used because of the relatively poor quality of her bone. She had no history or symptoms of coronary artery disease or heart failure. 
Surgery was complicated by an incidental durotomy which was repaired uneventfully. The total blood loss was $550 \mathrm{~mL}$. With extubation, the patient had some difficulty with congestion and was taken over to the postanesthesia care unit (PACU) on a Venturi mask. After some breathing treatments in the PACU, her airway cleared uneventfully and she was transferred to the floor.

The first two postoperative days were unremarkable. On the evening of postoperative day three, the patient developed a seven-hour course of chest pain which was described as squeezing in nature and associated with concurrent shortness of breath. AMI panels were obtained, and troponins peaked at 1.3. An ECG was obtained and demonstrated diffuse Twave inversions and T-wave flattening. An echocardiogram was obtained and demonstrated an ejection fraction of 30\%$35 \%$ with a left ventricular end-diastolic diameter of 4.6 and a left atrial diameter of 5.0.

There was akinesis of the anteroseptal wall, lateral wall, and apical wall. The echocardiogram was suggestive of an anteroseptal myocardial infarction versus a Takotsubo (stressed) cardiomyopathy. The patient subsequently underwent a left heart catheterization which demonstrated absence of atherosclerotic vascular disease. The left ventriculography demonstrated extensive anteroapical and inferior dyskinesis. The overall ejection fraction was reduced to $25 \%$. The patient had a previously documented left ventricular ejection of $65 \%$ earlier that month.

The patient was diagnosed with TC, paroxysmal atrial fibrillation, and anxiety. The remainder of the hospital course was event-free, in particular with absence of chest pain or evidence of shortness of breath. On the day of discharge, heart rate was 72 , blood pressure $108 / 60$, respiratory rate 18 , and oxygen saturation $95 \%$. The patient was discharged to a rehabilitation center on aspirin, furosemide, lisinopril, and metoprolol for her newly diagnosed cardiomyopathy.

At the three-month orthopedic followup, the patient had no back or leg pain and was mobilizing and walking well. She was treated in a lumbosacral (LSO) brace for the first 3 months and radiographs at that time demonstrated solid bony fusion masses bilaterally from L2 to L5. At the threemonth cardiac followup, the patient was doing well and did not describe any cardiac symptoms. Echocardiography showed a return of her ejection fraction to normal.

\section{Discussion}

Takotsubo cardiomyopathy is most common in postmenopausal women between the ages of 62 and 75 [7]. Relative estrogen deficiency in postmenopausal women, resulting in some endothelial dysfunction, may be one of the key predisposing factors linking them to TC [8]. Other predisposing factors include pheochromocytoma, thyroid storm, anaphylaxis, exogenous epinephrine administration, stroke, sepsis, Addison's disease, Guillain-Barre syndrome, and illicit drug use and withdrawal [9-24]. Finally, up to two-thirds of patients who experience TC carry a diagnosis of anxiety or depression $[25,26]$.
The relationship between stress and TC has been extensively studied. Rats pretreated with combination alpha- and beta-adrenergic receptor blockade have shown decreased instances of TC in emotional stress models [27]. Furthermore, a review of case reports found that 88 cases of TC were clearly associated with an acute or subacute emotional stressor [28]. Finally, when compared to Killip class III MI patients, TC patients had significantly higher levels of plasma catecholamines and stress neuropeptides [29].

There are multiple etiologic mechanisms that have been proposed to explain the development of TC. It has been argued that patients with an abnormal index of microvascular resistance are predisposed to TC. This is supported by reduction in coronary Doppler flow reserve and higher thrombolysis in myocardial frame counts when compared with controls [30, 31]. Another etiologic mechanism may involve left ventricular outflow tract obstruction as a result of septal bulging associated with systolic anterior motion of the mitral valve and mitral regurgitation [32]. This mechanism mimics that of hypertrophic cardiomyopathy. Multivessel epicardial spasms have also been proposed as a result of emergency coronarography showing no significant obstruction and positive provocative test in around $30 \%$ of cases [2, 33]. Finally, as previously discussed, increased catecholamines and the hormonal changes in postmenopausal women have been linked as etiologic mechanisms to the development of TC [2, 27, 29-32, 34-37].

Cardiac biomarkers are generally only slightly elevated in patients with TC. Furthermore, coronary angiography has shown that $80.6 \%$ of patients have normal coronary arteries and the remainder have luminal stenosis under 50\%. Acutely all patients with TC have moderate-to-severe midventricular dysfunction and apical akinesis or dyskinesis [6].

TC has a mortality of $1.1 \%$ [6]. The majority of survivors make a full recovery in which all wall abnormalities resolve completely. Acutely ill patients with TC present with ejection fractions in the range of $20 \%$ to $49 \%$. However, in just a matter of weeks, most patients have ejection fractions in the range of $60 \%$ to $76 \%[6]$.

Our patient was a postmenopausal 75-year-old female following a major spine surgery with significant perioperative blood loss. The physical and emotional demands of the surgery were significant for the patients, and her high anxiety was documented prior to and following her surgery. Her history of smoking and hypertension predisposed her to vascular dysfunction. Furthermore, her postsurgical anemia and challenging extubation may have also been precipitating factors in her development of TC.

Finally, it is also possible that enhanced stimulation of the sympathetic response by BMP played some role in precipitating the onset of TC. BMP has been used extensively in the last decade in spine surgery to enhance spinal fusions. Complications have been reported in association with its use, ranging from retrograde ejaculation to transient radiculitis and increased wound drainage [3]. Research has further suggested that BMP can have a profound effect on the sympathetic nervous system $[4,5]$. No previous reports of cardiac events in the perioperative period have been associated to the use of BMP. It is unknown whether large doses of BMP, as 
was employed in this patient, could contribute to increased sympathetic tone and, consequently, cardiac events in subsets of patients.

\section{Conclusion}

TC must be included in the differential of any patient presenting with acute coronary syndrome following a stressful event, particularly if the patient is a postmenopausal woman, has a history of anxiety or depression, or has a medical condition that may predispose him/her to TC. Further inquiry into the role of BMP in potentially precipitating sympathetic mediated cardiac events might also be warranted. As the population of those undergoing major orthopaedic surgery in the United States ages, awareness of TC as a unique clinical identity in postoperative patients becomes increasingly important.

\section{References}

[1] T. Ueyama, K. Kasamatsu, T. Hano, Y. Tsuruo, and F. Ishikura, "Catecholamines and estrogen are involved in the pathogenesis of emotional stress-induced acute heart attack," Annals of the New York Academy of Sciences, vol. 1148, pp. 479-485, 2008.

[2] S. Kurisu, I. Inoue, T. Kawagoe et al., "Time course of electrocardiographic changes in patients with tako-tsubo syndromecomparison with acute myocardial infarction with minimal enzymatic release," Circulation Journal, vol. 68, no. 1, pp. 77-81, 2004.

[3] M. Gianni, F. Dentali, A. M. Grandi, G. Sumner, R. Hiralal, and E. Lonn, "Apical ballooning syndrome or takotsubo cardiomyopathy: a systematic review," European Heart Journal, vol. 27, no. 13, pp. 1523-1529, 2006.

[4] J. Even, M. Eskander, and J. Kang, "Bone morphogenic protein in spine surgery: current and future uses," Journal of the American Academy of Orthopaedic Surgeons, vol. 20, no. 9, pp. 547-552, 2012.

[5] Y. Morikawa, A. Zehir, E. Maska et al., "BMP signaling regulates sympathetic nervous system development through Smad4dependent and -independentpathways," Development, vol. 136, no. 21, pp. 3575-3584, 2009.

[6] J. A. Goldstein, S. M. Kelly, P. P. LoPresit et al., "SMAD signaling drives heart and muscle dysfunction in a Drosophilia model of muscular dystrophy," Human Molecular Genetics, vol. 20, no. 5, pp. 894-904, 2011.

[7] K. A. Bybee, T. Kara, A. Prasad et al., "Systematic review: transient left ventricular apical ballooning: a syndrome that mimics ST-segment elevation myocardial infarction," Annals of Internal Medicine, vol. 141, no. 11, pp. 858-865, 2004.

[8] M. A. Leesar, "Takotsubo cardiomyopathy and microvascular dysfunction: another diagnostic criteria or predisposing factor?" Catheterization and Cardiovascular Interventions, vol. 77, no. 1, pp. 132-133, 2011.

[9] K. Dote, H. Sato, H. Tateishi, T. Uchida, and M. Ishihara, "Myocardial stunning due to simultaneous multivessel coronary spasms: a review of 5 cases," Journal of Cardiology, vol. 21, no. 2, pp. 203-214, 1991.

[10] E. Braunwald and R. A. Kloner, "The stunned myocardium: prolonged, postischemic ventricular dysfunction," Circulation, vol. 66 , no. 6 , pp. $1146-1149,1982$.
[11] V. Jindal, M. L. Baker, A. Aryangat, S. D. Wittlin, J. D. Bisognano, and H. S. Richter, "Pheochromocytoma: presenting with regular cyclic blood pressure and inverted Takotsubo cardiomyopathy," Journal of Clinical Hypertension, vol. 11, no. 2, pp. 81-86, 2009.

[12] C. Barcin, H. Kursaklioglu, S. Kose, B. Amasyali, and E. Isik, "Takotsubo cardiomyopathy in a patient with Addison disease: is apical ballooning always reversible?" International Journal of Cardiology, vol. 138, no. 1, pp. e15-e17, 2010.

[13] A. Radhakrishnan and J. E. Granato, "An association between takotsubo cardiomyopathy and thyroid storm," Postgraduate Medicine, vol. 121, no. 3, pp. 126-130, 2009.

[14] I. V. Litvinov, M. A. Kotowycz, and S. Wassmann, "Iatrogenic epinephrine-induced reverse Takotsubo cardiomyopathy: direct evidence supporting the role of catecholamines in the pathophysiology of the 'broken heart syndrome," Clinical Research in Cardiology, vol. 98, no. 7, pp. 457-462, 2009.

[15] E. H. Suk, D. H. Kim, T. D. Kweon, S. W. Na, and J. A. Shin, "Stress-induced cardiomyopathy following cephalosporininduced anaphylactic shock during general anesthesia," Canadian Journal of Anesthesia, vol. 56, no. 6, pp. 432-436, 2009.

[16] S. Yoshimura, K. Toyoda, T. Ohara et al., "Takotsubo cardiomyopathy in acute ischemic stroke," Annals of Neurology, vol. 64, no. 5, pp. 547-554, 2008.

[17] A. Frustaci, F. Loperfido, N. Gentiloni, M. Caldarulo, E. Morgante, and M. A. Russo, "Catecholamine-induced cardiomyopathy in multiple endocrine neoplasia: a histologic, ultrastructural, and biochemical study," Chest, vol. 99, no. 2, pp. 382-385, 1991.

[18] R. P. Martins, N. Barbarot, N. Coquerel, A. E. Baruteau, I. Kolev, and M. Vérin, "Takotsubo cardiomyopathy associated with Guillain-Barré syndrome: a differential diagnosis from dysautonomia not to be missed," Journal of the Neurological Sciences, vol. 291, no. 1-2, pp. 100-102, 2010.

[19] M. C. Cohen, M. S. Huberman, and R. W. Nesto, "Recombinant alpha2 interferon-related cardiomyopathy," American Journal of Medicine, vol. 85, no. 4, pp. 549-551, 1988.

[20] D. Jefic, D. Koul, A. Boguszewski, and W. Martini, “Transient left ventricular apical ballooning syndrome caused by abrupt metoprolol withdrawal," International Journal of Cardiology, vol. 131, no. 1, pp. e35-e37, 2008.

[21] F. Lemesle, F. Lemesle, W. Nicola, and A. Pierre Jonville-Béra, "First case of stress cardiomyopathy as a result of methadone withdrawal secondary to drug-drug interaction," American Journal of Emergency Medicine, vol. 28, no. 3, pp. 387.e5-387.e6, 2010.

[22] S. Arora, F. Alfayoumi, and V. Srinivasan, "Transient left ventricular apical ballooning after cocaine use: is catecholamine cardiotoxicity the pathologic link?" Mayo Clinic Proceedings, vol. 81, no. 6, pp. 829-832, 2006.

[23] N. W. C. J. van de Donk, Y. G. America, P. M. J. Zelissen, and B. J. B. Hamer, "Takotsubo cardiomyopathy following radioiodine therapy for toxic multinodular goitre," Netherlands Journal of Medicine, vol. 67, no. 10, pp. 350-352, 2009.

[24] J. C. Charniot, N. Vignat, J. J. Monsuez et al., "Cardiogenic shock associated with reversible dilated cardiomyopathy during therapy with regular doses of venlafaxine," American Journal of Emergency Medicine, vol. 28, no. 2, pp. 256.el-256.e5, 2010.

[25] M. R. Summers, R. J. Lennon, and A. Prasad, "Pre-morbid psychiatric and cardiovascular diseases in apical ballooning 
syndrome (tako-tsubo/stress-induced cardiomyopathy). Potential pre-disposing factors?" Journal of the American College of Cardiology, vol. 55, no. 7, pp. 700-701, 2010.

[26] J. R. Maldonado, P. Pajouhi, and R. Witteles, "Broken heart syndrome (takotsubo cardiomyopathy) triggered by acute mania: a review and case report," Psychosomatics, vol. 54, no. 1, pp. 74-79, 2013.

[27] T. Ueyama, K. Kasamatsu, T. Hano, K. Yamamoto, Y. Tsuruo, and I. Nishio, "Emotional stress induces transient left ventricular hypocontraction in the rat via activation of cardiac adrenoceptors: a possible animal model of "tako-tsubo" cardiomyopathy," Circulation Journal, vol. 66, no. 7, pp. 712-713, 2002.

[28] F. Sirois, "TakoTsubo syndrome and emotional stress: a heuristic approach," General Hospital Psychiatry, vol. 32, no. 4, pp. 447.e11-447.e13, 2010.

[29] I. S. Wittstein, D. R. Thiemann, J. A. C. Lima et al., "Neurohumoral features of myocardial stunning due to sudden emotional stress," The New England Journal of Medicine, vol. 352, no. 6, pp. 539-548, 2005.

[30] T. Kume, T. Akasaka, T. Kawamoto et al., "Assessment of coronary microcirculation in patients with takotsubo-like left ventricular dysfunction," Circulation Journal, vol. 69, no. 8, pp. 934-939, 2005.

[31] K. A. Bybee, A. Prasad, G. W. Barsness et al., "Clinical characteristics and thrombolysis in myocardial infarction frame counts in women with transient left ventricular apical ballooning syndrome," American Journal of Cardiology, vol. 94, no. 3, pp. 343-346, 2004.

[32] R. E. Mahmoud, N. Mansencal, R. Pilliére et al., "Prevalence and characteristics of left ventricular outflow tract obstruction in Tako-Tsubo syndrome," American Heart Journal, vol. 156, no. 3, pp. 543-548, 2008.

[33] T. M. Pilgrim and T. R. Wyss, "Takotsubo cardiomyopathy or transient left ventricular apical ballooning syndrome: a systematic review," International Journal of Cardiology, vol. 124, no. 3, pp. 283-292, 2008.

[34] Y. J. Akashi, K. Nakazawa, M. Sakakibara, F. Miyake, H. Musha, and K. Sasaka, "123I-MIBG myocardial scintigraphy in patients with "takotsubo" cardiomyopathy," Journal of Nuclear Medicine, vol. 45, no. 7, pp. 1121-1127, 2004.

[35] K. Ito, H. Sugihara, S. Katoh, A. Azuma, and M. Nakagawa, "Assessment of Takotsubo (ampulla) cardiomyopathy using 99mTc-tetrofosmin myocardial SPECT_comparison with acute coronary syndrome," Annals of Nuclear Medicine, vol. 17, no. 2, pp. 115-122, 2003.

[36] H. M. Nef, H. Möllmann, Y. J. Akashi, and C. W. Hamm, "Mechanisms of stress (Takotsubo) cardiomyopathy," Nature Reviews Cardiology, vol. 7, no. 4, pp. 187-193, 2010.

[37] Y. J. Akashi, H. M. Nef, H. Möllmann, and T. Ueyama, "Stress cardiomyopathy," Annual Review of Medicine, vol. 61, pp. 271286, 2010 . 


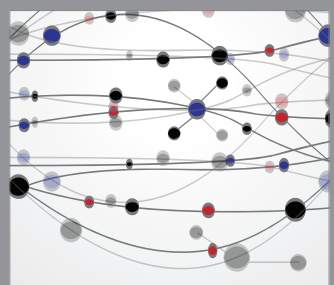

The Scientific World Journal
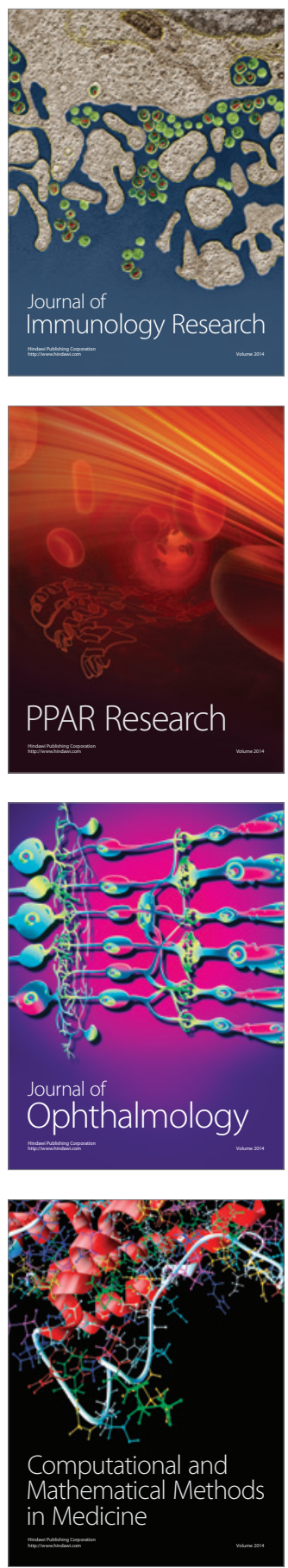

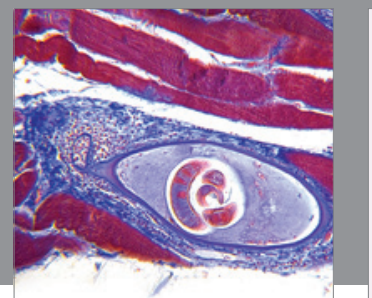

Gastroenterology

Research and Practice
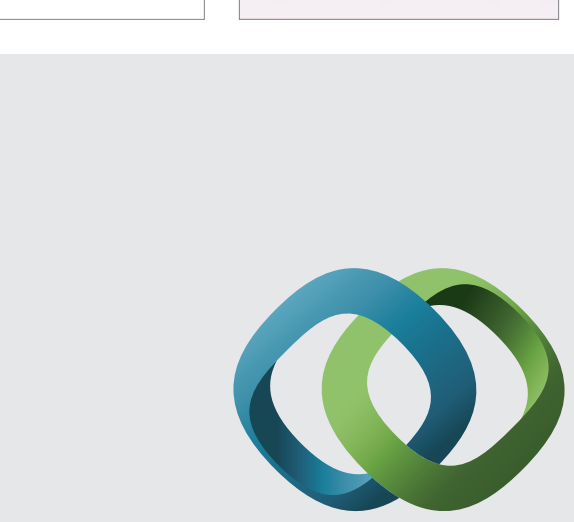

\section{Hindawi}

Submit your manuscripts at

http://www.hindawi.com
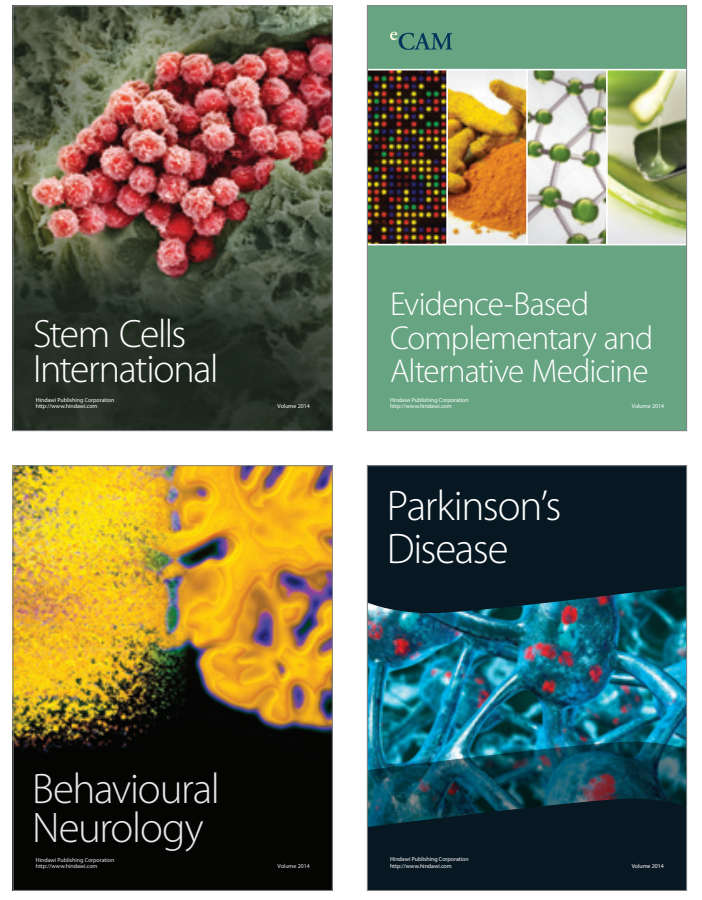
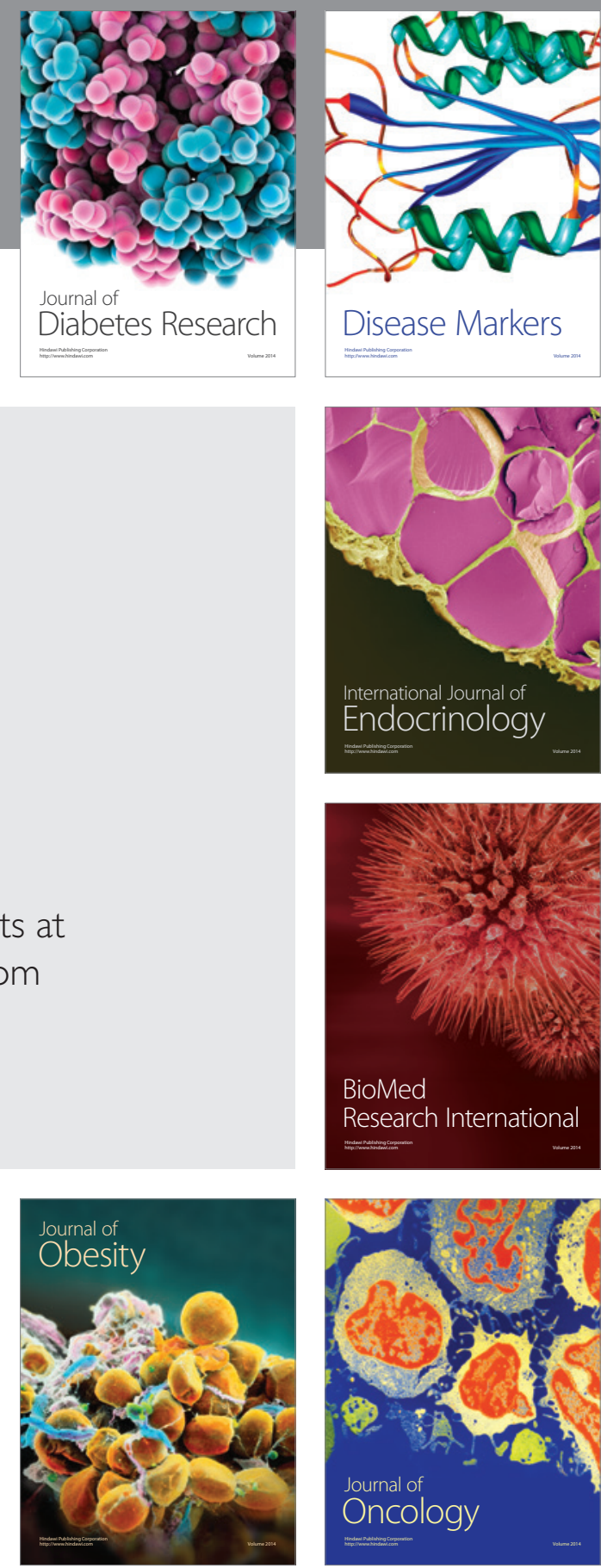

Disease Markers
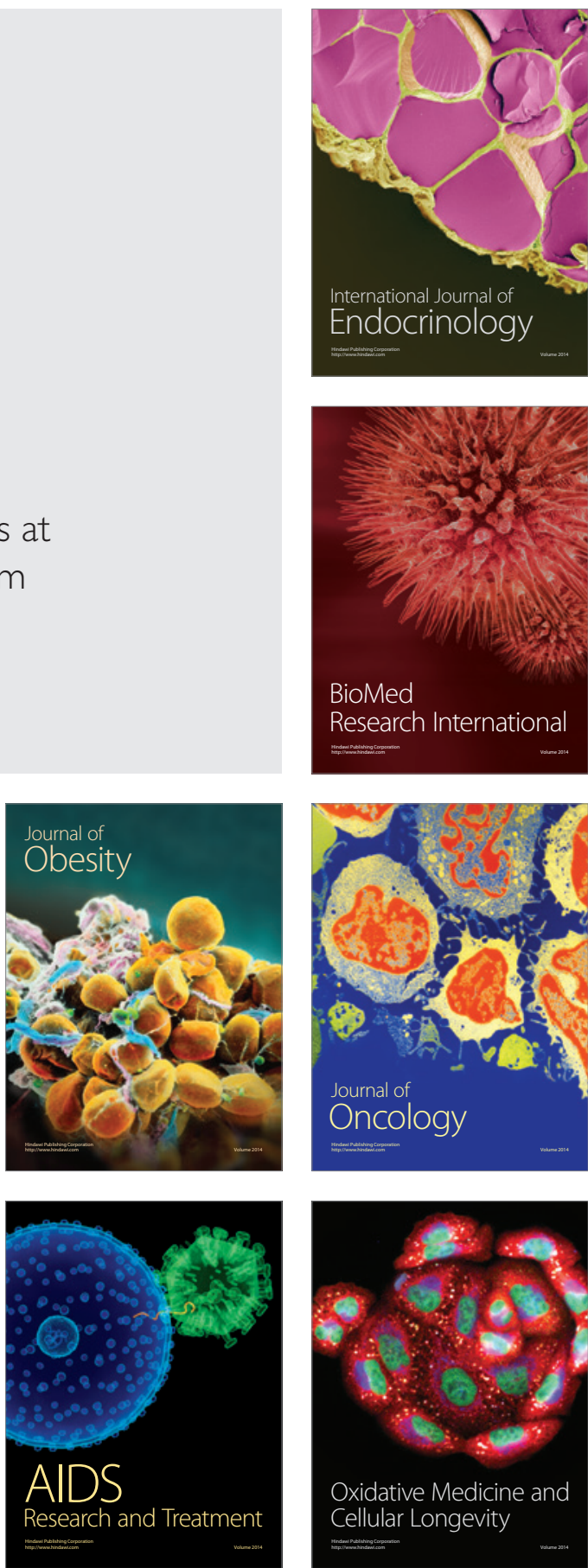